Nuevamente nos reencontramos en otra edición de la Revista Aula Universitaria. Desde la Facultad de Bioquímica y Ciencias Biológicas y de la Escuela Superior de Sanidad "Dr. Ramón Carrillo", llevamos a todos nuestros lectores la $18^{\circ}$ entrega de nuestra revista.

En este número nos ocupamos del análisis del proceso de Educación en Ciencias Experimentales que actualmente enfrenta serios problemas para mejorar su calidad y satisfacer las exigencias de la sociedad. El estado de situación actual nos muestra la necesidad de mejorar significativamente los resultados del aprendizaje de las disciplinas científicas en su conjunto, particularmente el de las ciencias naturales.

En este contexto, Aula Universitaria se propone cumplir un rol importante y productivo, por un lado, la difusión de nuevos conocimientos y experiencias de la actividad docente generada en nuestras aulas y otros niveles educativos. Por otro lado, convertirse en un sitio donde se discutan los problemas de la enseñanza y el aprendizaje de las Ciencias Naturales, observándolos desde su origen, y en ese sentido contribuir a la mejora de las prácticas docentes. Ofrecemos aquí Las experiencias exitosas realizadas por nuestros docentes para ser investigadas, analizadas, discutidas y definidas como soporte concreto desde una perspectiva trasformadora de la realidad en curso.

En esta edición, se incluyen también, los trabajos presentados en las $\mathbf{V}$ Jornada para el Fortalecimiento de la Enseñanza de la Enfermedad de Chagas en las Ciencias de la Salud, realizadas en Santa Fe en setiembre de 2016. Este tipo de jornadas fomentan el intercambio de experiencias sobre esta problemática entre autoridades, docentes, investigadores y esudiantes de las Facultades de Ciencias de la Salud de las Universidades Argentinas y permiten conocer las diferentes realidades, elaborar propuestas y/o recomendaciones, con una mirada integradora e interdisciplinaria, tendientes a fortalecer la enseñanza de la Enfermedad de Chagas. Consideramos de mucha importancia poder difundir en nuestra publicación estas actividades.

Esperamos que el material brindado en esta entrega sea de utilidad para seguir aportando al desarrollo de la educación en nuestro país. Entendemos que la necesidad de debate y discusión es indispensable, y es aquí donde pretendemos brindar un espacio válido para hacerlo. La educación tiene la misión trascendental de prepararnos para el futuro, si nuestra meta es generar profesionales académicamente preparados para desempeñarse en empleos exigentes, es tiempo de diseñar estrategias que los preparen para esos desafíos.

Javier Lottersberger

Decano - FBCB 


\section{A 20 años...}

No fue casualidad que, a no demasiado tiempo de conformarse el Gabinete Pedagógico de la Facultad de Bioquímica y Ciencias Biológicas, cristalizara la aparición del primer ejemplar de la Revista Aula Universitaria.

En 1996, el Consejo Directivo, como órgano de gobierno de la institución, decidió la conformación de un equipo de colaboración con la Directora del Gabinete, que incluía a docentes que se desempeñaban en cátedras ubicadas en distintos ciclos de la carrera de Bioquímica.

Este equipo interdisciplinario posibilitó un intercambio de opiniones desde miradas diferentes, abonándose un diálogo fecundo, que permitió vislumbrar los caminos conducentes a la superación de una problemática que limita la efectividad del accionar docente universitario.

La Pedagogía, como Ciencia de la Educación con su raíz humanística, y la Bioquímica, con predominio de disciplinas provenientes de las Ciencias Experimentales, parecen transitar por dos caminos paralelos.

La Didáctica, que se ocupa y profundiza en el método de enseñanza, es como una mano que se extiende hacia el docente universitario y no alcanza a brindarle herramientas eficaces.

Si la metodología no hunde sus raíces en el saber disciplinar, yviceversa, no es posible superar la inconmensurable distancia proveniente de dos formas distintas de pensamiento.

Un hito sumamente significativo fue la creación, incluido entre los posgrados de la institución, de la Maestría en Didáctica de las Ciencias Experimentales. Fue la concreción de la clara visión del Equipo de Gestión de apuntalar la formación pedagógica de los docentes, casi en su totalidad con título de grado Bioquímico, entendiendo que hay un conjunto de saberes científicos acerca de enseñary aprender que deben guiar los procesos educativos.

"Aula Universitaria es una reivindicación de la docencia en la universidad..." se dijo en el acto de presentación de la revista.Años después, expresaba el Secretario Académico en la editorial "Es habitual encontrar revistas que difundan los resultados de trabajos científicos, pero es menos frecuente que una publicación trate de efectuar un aporte específico destinado a facilitar y jerarquizar la labor docente", como ocurre en este caso.

Veinte años han transcurrido desde entonces y es otro el panorama que se aprecia hoy en nuestraFacultad. 
El permanente surgimiento de nuevas carreras, como las Licenciaturas en Nutrición y en Biotecnología yel desarrollo de laEscuela Superior de Sanidad, con sus diversas carreras de pregrado y de grado,fueron aumentando notablemente la necesidad de jerarquizar el objetivo propuesto.Se ha requerido de docentes con sólida formación disciplinar, para respetar la propia lógica desde lo epistemológico, pero también con dominio de herramientas que posibiliten una adecuada transposición didáctica de esos contenidos y promuevan las prácticas idiosincráticas y específicasde cada una.

Por su parte, la Directora de la Revista y responsable del Gabinete Pedagógico, a lo largo de este tiempo transcurrido, no desaprovechó este instrumento para difundir y reforzar en sus sucesivas editoriales los aspectos críticos que hacen a una buena enseñanza, a la búsqueda de estrategias centradas en la comprensión, una enseñanza que se preocupa del devenir de los procesos formativos que promueve."Las instituciones universitarias tienen la misión de potenciar alumnos críticos, analíticos, innovadores, y con un alto nivel de desarrollo de los valores humanos".

Comunicar Experiencias pedagógicas, dándoles un marco de fundamentación teóri$\mathrm{ca}$, promueve a los profesores a considerar sus acciones en el aula, en relación con los contextos históricos, sociales y culturales, en los que su enseñanza está inserta.

Publicar Reflexiones teóricas o metodológicas, socializando los saberes alcanzados mediante el estudio y meta evaluación de los propios procesos, son experiencias enriquecedoras.

Dar a conocer Investigaciones didácticas, formuladas con un diseño experimental innovador, sustentado en estudios previos, cuyo desarrollo permita obtener sólidas conclusiones, moviliza al cuerpo docente de esta universidad y de otras instituciones.

En este punto, se ha hecho especial hincapié en que los profesores, ya sea en forma individual, y más aún colectivamente, se transformen en investigadores de su propia práctica, involucrándose en su análisis y revisión, lo cual invita a la comprensión crítica más que a la aceptación de lo que hace y va permitiendo lograr un perfeccionamiento de su labor, apoyándose en la investigación.

Desde aquel primer ejemplar, que no contó por única vez, con un Comité de Evaluación Externo, pasando por la conformación del mismo con especialistas locales y de otras universidades del país, nos encontramos hoy con un Comité de Evaluación integrado por destacados expertos de nivel internacional, que jerarquizan nuestra revista.

Por otra parte, Aula Universitaria ha sido evaluada en el Nivel 1 Catálogo Latindex del CAICYT.

Por su trayectoria se ha constituido en el canal adecuado para la comunicación de trabajos de colegas de diferentes países de América Latina.

Jerarquizar al docente investigador, brindando canales de perfeccionamiento, es poner a la enseñanza en el comienzo y en el fin de la misión de la universidad.

Alicia Costamagna Miembro del Comité Editorial de Aula Universitaria 